\title{
A ESCOLA DE TEMPO INTEGRAL NO BRASIL: TRAJETÓRIA HISTÓRICA E LEGAL
}

\author{
Silvio Cesar Nunes Militão, Andressa Neves Kiill
}

Universidade Estadual Paulista - UNESP, curso de Pedagogia, Presidente Prudente, SP. E-mail: scnmilitao@gmail.com. Agência de fomento: CNPq/PIBIC.

\section{RESUMO}

No contexto contemporâneo brasileiro a temática da escola de tempo integral, cada vez, mais ganha força na agenda política e centralidade no debate educacional. Assim, este artigo, resultante de uma pesquisa de iniciação científica (CNPq/PIBIC) em desenvolvimento, objetivou investigar e analisar a trajetória histórica e legal concernente ao tema da escola de tempo integral no Brasil. Para tanto, se valeu dos seguintes procedimentos metodológicos: pesquisa bibliográfica e pesquisa documental acerca da temática em tela. Os resultados da pesquisa indicam que, superada a longa fase das experiências pontuais e esparsas de implantação da escola de tempo integral no país, o Brasil caminha agora no sentido da consolidação de uma política pública nacional em prol da ampliação do tempo de permanência na escola, caracterizada pela continuidade e maior abrangência. Concluímos, entretanto, que muito se falta a percorrer ainda para a universalização da escola de tempo integral.

Palavras-chave: escola, tempo integral, legislação educacional, políticas públicas, Brasil.

\section{A SCHOOL FULL-TIME IN BRAZIL: HISTORICAL AND LEGAL PATH}

\begin{abstract}
In the Brazilian contemporary context the issue of school full-time, every time, more gains strength on the political agenda and centrality in the educational discussion. So this article resulting from an undergraduate research (CNPq/PIBIC) in development, aimed to investigate and analyze the historical and legal trajectory concerning the subject of full-time school in Brazil. To this end, drew the following methodological procedures: literature search and information retrieval on the screen theme. The survey results indicate that once the long phase of point and scattered experiences of implementation of the full-time school in the country, Brazil now moving towards the consolidation of a national public policy in favor of the extension of time spent in school, characterized by continuity and greater coverage. We conclude, however, that much is lacking still go to the universalization of school full time.
\end{abstract}

Keywords: school, full-time, educational legislation, public policies, Brazil. 


\section{INTRODUÇÃO}

A proposta de escola de tempo integral, que não se constitui uma novidade histórica no Brasil, vem crescentemente ganhando força na agenda política e centralidade no debate educacional contemporâneo.

Defendida com entusiasmo por educadores, gestores, políticos e especialistas como estratégia imprescindível para a melhoria da educação brasileira, "[...] há cada vez mais adesões dos governos municipais e estaduais à escola de tempo integral [...]" (MIRANDA; SANTOS, 2012, p. 1077).

Abordar o tema da escola de tempo integral no momento presente e suas perspectivas futuras requer, necessária e inicialmente, a identificação e o exame tanto das principais experiências de implantação da escolarização pública em tempo integral no país quanto do conjunto legal construído nacionalmente para normatizar/regular tal matéria no âmbito do território brasileiro.

Assim, o presente artigo - fruto de uma pesquisa de iniciação científica em desenvolvimento e financiada pelo Conselho Nacional de Desenvolvimento Científico e Tecnológico (CNPq/PIBIC) - objetivou investigar e analisar a trajetória histórica e legal concernente à temática da escola de tempo integral no Brasil, tendo em vista desvelar as suas possíveis contribuições e implicações para a ampliação de tal formato escolar no contexto contemporâneo.

\section{METODOLOGIA}

A abordagem metodológica da investigação proposta foi a de natureza qualitativa (LÜDKE; ANDRÉ, 1986), contemplando: pesquisa bibliográfica e pesquisa documental acerca da temática em tela.

Primeiro passo de toda pesquisa científica, a pesquisa bibliográfica envolveu o levantamento, a seleção e o estudo de diversas publicações (artigos científicos, livros, dissertações, teses etc.) relacionadas ao tema em abordagem, permitindo a construção do referencial teórico do presente trabalho.

A pesquisa documental, por sua vez, envolveu a seleção, exploração e análise dos documentos oficiais - notadamente da legislação de alcance nacional - referentes à escola de tempo integral.

A análise final foi realizada à luz do objetivo precípuo do estudo e do referencial teórico norteador da pesquisa. 


\section{RESULTADOS}

Inicialmente, os resultados da pesquisa realizada evidenciam que até a década de 1990 tivemos no Brasil sete experiências emblemáticas de implantação da escola de tempo integral, conforme pode ser verificado no Quadro 1.

Quadro 1. Experiências pioneiras e históricas de implantação da escolarização de tempo integral no Brasil

\begin{tabular}{|c|c|c|c|}
\hline $\begin{array}{c}\text { Principais } \\
\text { Experiências }\end{array}$ & Década & Local & Breve descrição da experiência \\
\hline $\begin{array}{c}\text { Centro } \\
\text { Educacional } \\
\text { Carneiro } \\
\text { Ribeiro } \\
\text { (CECR) }\end{array}$ & 1950 & $\begin{array}{l}\text { Salvador } \\
\text { (BA) }\end{array}$ & $\begin{array}{l}\text { Em 1950, Anísio Teixeira concretizou a ideia de escola de } \\
\text { tempo integral, inaugurando o Centro Educacional Carneiro } \\
\text { Ribeiro (CECR), na cidade de Salvador, que visava resgatar a } \\
\text { qualidade do ensino, num complexo de quatro escolas- } \\
\text { classe e uma escola-parque (FERREIRA, 2007). } \\
\text { "No Centro, além da instrução e da educação, o aluno } \\
\text { receberia merenda, uniforme, material didático, livros e } \\
\text { atendimento médico e dentário" (EBOLI, 1971, p. } 71 \text { apud } \\
\text { CASTRO, 2009, p. 46). }\end{array}$ \\
\hline $\begin{array}{l}\text { Centro de } \\
\text { Educação } \\
\text { Elementar } \\
\text { (CEE) }\end{array}$ & 1960 & $\begin{array}{c}\text { Brasília } \\
\text { (DF) }\end{array}$ & $\begin{array}{l}\text { Inspirada na experiência pioneira do CECR, a construção do } \\
\text { Centro de Educação Elementar (CEE) em Brasília-DF ocorreu } \\
\text { em 1960, também idealizada por Anísio Teixeira. } \\
\text { De acordo com Dib (2010), o CEE possuía um conjunto de } \\
\text { prédios escolares para abrigar um Jardim de Infância, quatro } \\
\text { Escolas-Classe e uma Escola-parque. Após o jardim de } \\
\text { infância para as crianças de } 4 \text { a } 6 \text { anos, os alunos } \\
\text { ingressariam na Escola-Classe, cujo objetivo era a educação } \\
\text { intelectual e sistemática para crianças de } 7 \text { a } 14 \text { anos, e } \\
\text { paralelamente, complementariam sua formação na Escola- } \\
\text { Parque, onde seria desenvolvido o artístico, físico e } \\
\text { recreativo, bem como a sua iniciação ao trabalho, possuindo } \\
\text { assim uma jornada escolar de oito horas diárias. }\end{array}$ \\
\hline $\begin{array}{c}\text { Ginásios } \\
\text { Vocacionais } \\
\text { (GV) }\end{array}$ & 1960 & $\begin{array}{l}\text { Estado } \\
\text { de São } \\
\text { Paulo }\end{array}$ & $\begin{array}{l}\text { A experiência dos Ginásios Vocacionais (GV) do Estado de } \\
\text { São Paulo visava renovar o ensino secundário no território } \\
\text { paulista, através da permanência do aluno na escola em } \\
\text { tempo integral (DIB 2010). } \\
\text { Conforme Dib (2010), os primeiros GV foram criados em } \\
1962 \text { e tinham como proposta o ensino de tempo integral } \\
\text { para os jovens de ambos os sexos, com idade de ingresso de } \\
11 \text { a } 13 \text { anos. } \\
\text { Os GV possuíam uma organização em quatro anos e um } \\
\text { currículo diversificado, dividido em duas etapas de dois } \\
\text { anos: a Iniciação Vocacional, que abrangia duas séries } \\
\text { escolares, desenvolvidas em dois anos letivos, e o Ginásio } \\
\text { Vocacional completo, constituído pelas quatros séries. }\end{array}$ \\
\hline $\begin{array}{l}\text { Centros } \\
\text { Integrados }\end{array}$ & 1980 & $\begin{array}{l}\text { Estado } \\
\text { do Rio }\end{array}$ & $\begin{array}{l}\text { Os Centros Integrados de Educação Pública (CIEPs) foram } \\
\text { implementados por Darcy Ribeiro na década de 1980, que }\end{array}$ \\
\hline
\end{tabular}




\begin{tabular}{|c|c|c|c|}
\hline $\begin{array}{c}\text { de Educação } \\
\text { Pública } \\
\text { (CIEPs) }\end{array}$ & & $\begin{array}{c}\text { de } \\
\text { Janeiro }\end{array}$ & $\begin{array}{l}\text { na época era vice-governador do Rio de Janeiro durante o } \\
\text { governo de Leonel Brizola (PDT). No Brasil, o CIEP foi a } \\
\text { primeira escola popular de dia completo, como salienta } \\
\text { Castro (2009). } \\
\text { Os CIEPs, inaugurados em 1985, objetivavam promover um } \\
\text { salto na qualidade no ensino fundamental do estado, } \\
\text { proporcionando a escola de tempo integral como uma } \\
\text { forma de auxílio para o caos social em que crianças e } \\
\text { adolescentes de baixa renda se encontravam. Dessa forma, } \\
\text { incumbiu a educação da responsabilidade de resolver os } \\
\text { problemas sociais. Em cada unidade do CIEP era previsto a } \\
\text { frequência de } 600 \text { alunos, em regime de turno completo, de } \\
9 \text { horas diárias, oferecendo ensino de 1a a } 8 \text { a séries. Os } \\
\text { alunos teriam direito a quatro refeições, banho, atividades } \\
\text { esportivas, estudo dirigido e assistência médica- } \\
\text { odontológica (CUNHA, } 2005 \text { apud FERREIRA, 2007). }\end{array}$ \\
\hline $\begin{array}{l}\text { Programa } \\
\quad \text { de } \\
\text { Formação } \\
\text { Integral da } \\
\text { Criança } \\
\text { (PROFIC) }\end{array}$ & 1980 & $\begin{array}{l}\text { Estado } \\
\text { de São } \\
\text { Paulo }\end{array}$ & $\begin{array}{l}\text { Segundo Ferreti, Vianna e Souza (1991), o Programa de } \\
\text { Formação Integral da Criança (PROFIC), formulado em São } \\
\text { Paulo em 1986, foi um programa de repasse de verbas a } \\
\text { escolas das redes públicas, prefeituras ou entidades } \\
\text { particulares conveniadas, a fim de receber alunos das redes } \\
\text { públicas que queriam aderir ao Programa. Os alunos } \\
\text { frequentavam a escola que estavam devidamente } \\
\text { matriculados e no período correspondente ao outro turno, } \\
\text { permaneciam na escola ou se dirigiam até as entidades } \\
\text { conveniadas, onde se alimentavam e participavam de } \\
\text { atividades complementares, tais como, atividades } \\
\text { esportivas, artísticas, de lazer, pré-profissionalizante e de } \\
\text { reforço escolar. Para os alunos serem selecionados e } \\
\text { inscritos para participarem desse programa eram } \\
\text { averiguadas as características econômico-sociais e/ou seu } \\
\text { desempenho escolar. } \\
\text { O PROFIC não teve suas origens através de movimentos } \\
\text { populares por educação ou reivindicações dos profissionais } \\
\text { da educação pelo tempo integral dos alunos na escola, mas } \\
\text { foi pensado originalmente na UNICAMP, no segundo } \\
\text { semestre de 1986 e foi adaptado pela Secretaria de } \\
\text { Educação do Estado, possuindo características distintivas } \\
\text { (FERRETI; VIANNA; SOUZA, 1991). } \\
\text { O PROFIC tinha como principais objetivos ampliar o tempo } \\
\text { de permanência das crianças na escola enquanto seus pais } \\
\text { trabalhavam, visava à formação integral da criança e auxiliar } \\
\text { na melhoria do desempenho escola. }\end{array}$ \\
\hline $\begin{array}{c}\text { Centros } \\
\text { Integrados } \\
\text { de Apoio à } \\
\text { Criança } \\
\text { (CIACs) }\end{array}$ & 1990 & Nacional & $\begin{array}{l}\text { Em 1991, o Presidente Fernando Collor de Melo, consoante } \\
\text { com o Projeto Minha Gente, anunciou a implementação de } \\
\text { diversas escolas no Brasil, de ensino fundamental em } \\
\text { horário integral, os denominados Centros Integrados de } \\
\text { Apoio à Criança (CIACs), ligados ao Ministério da Saúde } \\
\text { (CASTRO, 2009). }\end{array}$ \\
\hline
\end{tabular}




\begin{tabular}{|c|c|c|c|}
\hline & & & $\begin{array}{l}\text { O Presidente Collor ao anunciar o Projeto Minha Gente, } \\
\text { visava a implementação de } 5.000 \text { escolas de ensino } \\
\text { fundamental em horário integral no Brasil, que abrigariam } 6 \\
\text { milhões de crianças e jovens e } 500 \text { mil adultos na } \\
\text { alfabetização no período noturno. Nessa escola, as crianças } \\
\text { permaneceriam por oito horas diárias, estudando, jogando e } \\
\text { aprendendo. As crianças também receberiam três } \\
\text { alimentações, assistência médica, dentária e educação sobre } \\
\text { higiene básica. O primeiro CIAC foi inaugurado em outubro } \\
\text { de 1992, e muitos educadores desejavam possuir uma } \\
\text { unidade educacional no seu Estado, pois a proposta } \\
\text { pedagógica desse projeto era atraente a princípio (DIB, } \\
\text { 2010). }\end{array}$ \\
\hline $\begin{array}{c}\text { Centros de } \\
\text { Atenção } \\
\text { Integral à } \\
\text { Criança } \\
\text { (CAICs) }\end{array}$ & 1990 & Nacional & $\begin{array}{l}\text { Ao assumir a Presidência da República por força do } \\
\text { impeachment de Collor, o Presidente Itamar Franco (1992) } \\
\text { transformou o CIAC em Centros de Atenção Integral à } \\
\text { Criança (CAICs). } \\
\text { Para Dib (2010), os CAICs possuíam dois objetivos } \\
\text { específicos, que era oferecer as famílias marginalizadas } \\
\text { condições para que seus filhos frequentassem a escola, local } \\
\text { em que seria oferecido as crianças o que as famílias não } \\
\text { teriam condições de oferecer, como por exemplo comida, } \\
\text { vestuário (uniforme), assistência médica-odontológica e } \\
\text { evitar que essas crianças entrassem precocemente no } \\
\text { mercado de trabalho(subempregos). Esses objetivos visavam } \\
\text { diminuir o índice de evasão e repetência escolar. }\end{array}$ \\
\hline
\end{tabular}

Fonte: Pesquisa realizada.

Posteriormente, os resultados obtidos pela presente pesquisa demonstram que na segunda metade da última década do século XX tem início no país a construção de uma política pública nacional voltada à escola de tempo integral, que ganha notável consistência a partir da edição de um correspondente conjunto legal, como é possível ser visualizado no Quadro 2.

Quadro 2-A escola de Tempo Integral no ordenamento legal contemporâneo

\begin{tabular}{|c|c|}
\hline Leis & Tempo Integral \\
\hline $\begin{array}{l}\text { LDB/96 } \\
\text { Lei no } \\
9.394 / 96\end{array}$ & $\begin{array}{l}\text { ensino fundamental incluirá pelo menos quatro } \\
\text { sala de aula, sendo progressivamente ampliado o } \\
\text { scola. } \\
\text { I será ministrado progressivamente em tempo } \\
\text { as de ensino. }\end{array}$ \\
\hline $\begin{array}{c}\text { PNE I } \\
\text { Lei } n \text { o } \\
10.172 / 20 \\
\end{array}$ & $\begin{array}{l}\text { rnada escolar visando expandir a escola } \\
\text { íodo de pelo menos sete horas diárias, } \\
\text { ios em número suficiente. }\end{array}$ \\
\hline $\begin{array}{l}\text { FUNDEB } \\
\text { EC no 53/06 e } \\
\text { Lei no }\end{array}$ & $\begin{array}{l}\text { Constitui-se num marco histórico do movimento legal em prol da conquista do } \\
\text { direito à educação escolar em tempo integral, uma vez que direciona recursos } \\
\text { para a oferta da educação básica em tal formato (COELHO; MENEZES, 2007). }\end{array}$ \\
\hline
\end{tabular}




\begin{tabular}{|c|c|}
\hline $11.494 / 2007$ & \\
\hline $\begin{array}{c}\text { PME } \\
\text { Decreto } n^{\circ} \\
7.083 / 2010\end{array}$ & $\begin{array}{l}\text { Artigo 10 - Contribuir para a melhoria da aprendizagem por meio da ampliação } \\
\text { do tempo de permanência de crianças, adolescentes e jovens matriculados em } \\
\text { escola pública, mediante oferta de educação básica em tempo integral. }\end{array}$ \\
\hline $\begin{array}{l}\text { PNE II } \\
\text { Lei } n= \\
13.005 / 14\end{array}$ & $\begin{array}{l}\text { META 6- oferecer educação em tempo integral em, no mínimo, } 50 \% \text { (cinquenta } \\
\text { por cento) das escolas públicas, de forma a atender, pelo menos, } 25 \% \text { dos } \\
\text { alunos da educação básica. }\end{array}$ \\
\hline
\end{tabular}

Fonte: Pesquisa realizada.

\section{DISCUSSÃO}

No Brasil, a ideia de escola em tempo integral começa a se desenvolver no início do século XX, sob influência dos escolanovistas, ganhando força a partir do Manifesto dos Pioneiros. Entretanto, como apresentado na seção anterior, ao longo das décadas tivemos apenas algumas experiências de implementação da escola de tempo integral no país, tais como: o CECR, de Salvador-BA; o CEE, de Brasília-DF; os GV, no Estado de São Paulo, os CIEPs, no Estado do Rio de Janeiro; o PROFIC, no estado paulista; e os CIACs e CAICs, em âmbito nacional. Essas experiências, apesar de emblemáticas em termos de conquistas em relação ao tempo integral, foram incipientes do ponto de vista da abrangência da implantação da escola de tempo integral no Brasil até meados dos anos 1990. É somente com o advento da Lei de Diretrizes e Bases da Educação Nacional - Lei no 9.394/96 (LDB/96) que a escola de tempo integral ganha maior importância no debate educacional contemporâneo e tratamento de alcance nacional, reforçada posterior e complementarmente pelo seguinte ordenamento jurídico referente à matéria: Plano Nacional de Educação (PNE) I e II (Leis no 10.172/2001 e no 13.005/2014, respectivamente); Fundo de Manutenção e Desenvolvimento da Educação Básica e de Valorização dos Profissionais da Educação (FUNDEB), instituído pela Emenda Constitucional no 53/2006 e regulamentado pela Lei no 11.494/2007; e Programa Mais Educação (PME), disciplinado pelo Decreto no 7.085/2010, abrindo caminho e criando condições mais objetivas para sua crescente expansão no Brasil.

Mesmo com suas marchas e contramarchas, a LDB/96 trouxe a perspectiva da escola de tempo integral em âmbito nacional, reconhecendo-a como uma das bases para o desenvolvimento do educando.

Segundo Coelho e Menezes (2007, p. 4), a LDB/96 avança ao preconizar "a ampliação gradativa do tempo de permanência na escola na forma da progressiva implantação do ensino fundamental de tempo integral", embora deixe o seu planejamento e implantação a critério dos sistemas de ensino.

Ao analisar o conteúdo do PNE I, Menezes (2008, P. 4) observa que ele, tal qual a LDB/96, retoma e valoriza a educação integral, como possibilidade de formação integral do individuo. 
Conforme a autora, o PNE I avança para além do texto da LDB, pois propõe a ampliação progressiva do tempo escolar tanto para o ensino fundamental (como já fazia a LDB/96) quanto para a educação infantil (novidade trazida pelo PNE I).

O PNE II, que possui 20 metas para todos os níveis e modalidades de ensino a serem alcançadas até o final de 2024, com o objetivo geral de melhorar a qualidade e a oferta da educação brasileira, tal qual o PNE I já expirado, também dedica meta exclusiva (a meta de número 6) para a questão da escola de tempo integral. Textualmente: "oferecer educação em tempo integral em, no mínimo, 50\% (cinquenta por cento) das escolas públicas, de forma a atender, pelo menos, $25 \%$ dos alunos da educação básica".

Embora reconheça que a meta supracitada "é muito importante para a melhoria efetiva da educação pública brasileira", Brandão (2014, p. 38) também a considera "razoavelmente modesta", pois, ao invés de, em 10 anos, propor que metade das escolas públicas ofereçam educação em tempo integral, poderia ter proposto que em 2024 todas as escolas públicas fossem de tempo integral.

Diferentemente do Fundo de Manutenção do Ensino Fundamental e de Valorização do Magistério (FUNDEF), vigente até 2006 e que não previa nada em prol da educação de tempo integral, o FUNDEB considera o tempo integral como uma possibilidade para toda a educação básica nacional e associa a essa modalidade coeficientes de distribuição de recursos, num esforço inicial de "garantir o real direito à educação em tempo integral", pois "o direito só se realiza de fato quando associado a fontes significativas e estáveis de recursos" (MENEZES, 2008, p.7).

Scalabrin $(2012$, p. 7) acredita que, se a educação em tempo integral é uma das maneiras capazes de auxiliar para a qualificação da educação, há que se investir mais nela, pois "a questão do financiamento da educação é determinante para a ampliação do tempo educativo com qualidade".

A ampliação da escola de tempo integral no Brasil ganha fôlego, ainda, com o advento do Programa Mais Educação, disciplinado pelo Decreto no 7.083/2010.

Tal Programa constitui-se em estratégia do Governo Federal “[...] para indução da ampliação do tempo escolar nas redes estaduais e municipais de ensino, por meio da oferta de atividades optativas em diferentes áreas, com o objetivo de ampliar a jornada escolar nas escolas públicas para, no mínimo, sete horas diárias" (MIRANDA; SANTOS, 2012, p. 1078).

Com o decisivo e imprescindível apoio do Governo Federal, expresso pelo Programa Mais Educação, a política pública de escola de tempo integral passa a adquirir maior consistência no Brasil e as experiências, sobretudo municipais, a despontar por todo o país. 


\section{CONCLUSÃO}

Historicamente fruto de iniciativas pontuais e esparsas de distintos governos subnacionais, as experiências de implantação da escolarização pública em tempo integral levada a cabo no Brasil até a primeira metade dos anos 1990 foram parcas e de alcance limitado.

Reconhecidamente um fator importante para a melhoria da qualidade da educação, a oferta da escola em tempo integral passou a configurar-se como uma política pública nacional e consistente apenas na contemporaneidade, por conta tanto do ordenamento legal que passa a vigorar nas duas últimas décadas quanto da forte indução decorrente da instituição do Programa Mais Educação.

Assim, cada vez mais vem despontando por todo o país experiências de implantação da escola de tempo integral, tanto nas redes estaduais quanto nas municipais.

Entretanto, apesar do crescimento recente e considerável, a ampliação do tempo de permanência dos alunos na escola em escala nacional constitui-se num enorme desafio nacional, pois ainda há muito que percorrer e alcançar no tocante à universalização da escola de tempo integral.

\section{REFERÊNCIAS}

BRANDÃO, Carlos da Fonseca. PNE (Lei $\mathbf{n}^{\circ}$ 10.172/2001): Discussão dos Objetivos e Metas do Plano Nacional de Educação. São Paulo: Avercamp, 2006.

BRASIL. Lei no 13.005, de 25 de junho de 2014. Aprova o Plano Nacional de Educação e dá outras providências. Diário Oficial da União, Brasília, DF, 26. jun. 2014. Seção 1, p.01.

Decreto no 7.083, de 27 de janeiro de 2010. Dispõe sobre o Programa Mais Educação. Brasília: 2010.

Lei no 11.494, de 20 de junho de 2007. Regulamenta o Fundo de Manutenção e Desenvolvimento da Educação Básica e de Valorização dos Profissionais da Educação - FUNDEB, e dá outras providências. Brasília: 2007.

. Emenda Constitucional no 53, de 19 de dezembro de 2006. Dá nova redação aos artigos 70 , 23, 206, 208, 211 e 212 da Constituição Federal e ao artigo 60 do Ato das Disposições Constitucionais Transitórias. Brasília: 2006.

. Lei no 10.172, de 09 de janeiro de 2001. Aprova o Plano Nacional de Educação e dá outras providências. Brasília, 2001.

. Lei no 9.394, de 20 de dezembro de 1996. Dispõe sobre as Diretrizes e Bases da Educação Nacional. Brasília: 1996. 
CASTRO, A. de. A escola de tempo integral: a implantação do projeto em uma escola do interior paulista. 2009.218 f. Defesa no programa de Pós-Graduação em Educação- Universidade Federal de São Carlos, São Carlos.

COELHO, L. M. C. da C.; MENEZES, J. S. da S. Tempo integral no ensino fundamental: ordenamento constitucional-legal em discussão. In: 30ạ. Reunião Anual da Associação Nacional de Pós-Graduação e Pesquisa em Educação (ANPEd), 2007, Caxambu, Anais..., 2007, p. 1-16.

DIB, M. A. B. O programa escola de tempo integral na região de Assis: implicações para a qualidade de ensino. 2010. 207 f. Tese (Doutorado em Educação) - FFC/UNESP, Marília.

FERREIRA, C. M. P. D. S. Escola em tempo integral: possível solução ou mito na busca da qualidade? 2007. 58 f. Dissertação (Programa de Pós-Graduação em Educação)- UEL, Londrina.

LÜDKE, M.; ANDRÉ, M. E. D. A. Pesquisa em educação: abordagens qualitativas. São Paulo: EPU, 1986.

FERRETI, C. J.; VIANNA, C. P.; SOUZA, D. T. de. Escola pública em tempo integral: o Profic na rede estadual paulista. Cadernos de Pesquisa, São Paulo, n. 76, p. 5-17, fev. 1991.

MENEZES, J. S. S. . Educação integral e tempo integral na educação básica: da LDB ao PDE. In: IV Simpósio Internacional: O Estado e as Políticas Educacionais no tempo presente, 2008, Uberlândia, Anais... , 2008. p. 01-17.

MIRANDA, M. de G.; SANTOS, S. V. Propostas de tempo integral: a que se destina a ampliação do tempo escolar? Perspectiva, Florianópolis, v. 30, n. 3, 1073-1098, set./dez.. 2012.

SCALABRIN, I. Educação em tempo integral: como pagar a conta? Revista de financiamento da educação. Porto alegre, v.2, n.2, 2012. 